\title{
The impact of local US tobacco policies on youth tobacco use: a critical review
}

\author{
Karen B. Friend $^{1^{*}}$, Sharon Lipperman-Kreda ${ }^{2}$, Joel Grube ${ }^{2}$ \\ ${ }^{1}$ The Decision Sciences Institute, Pacific Institute for Research and Evaluation, Pawtucket, USA; \\ *Corresponding author: kfriend@pire.org \\ ${ }^{2}$ Prevention Research Center, Pacific Institute for Research and Evaluation, Berkeley, USA.
}

Received 25 May 2011; revised 14 July 2011; accepted 31 July 2011.

\begin{abstract}
Tobacco use continues to be the leading preventable cause of premature death in the United States, killing over 430,000 people annually. Tobacco initiation and use among youth remains a significant public health concern. Despite declines in US youth tobacco use in recent years, state and national survey results are still cause for alarm. Although traditional school-based curricular programs are the most common strategy to prevent or reduce youth tobacco use, their effectiveness may be limited because young people are immersed in a broader social context in which tobacco is readily available. Environmental strategies change this social context by focusing on policy, enforcement, and media. A compelling body of evidence suggests that interventions at the state and federal levels can, when implemented in combination, reduce youth tobacco use. The impact of policies implemented at the local levels is less well understood and effects of environmental strategies on smokeless tobacco consumption have been largely ignored. The purpose of this paper is to review the literature on environmental strategies implemented at the local level on youth use of both cigarettes and smokeless tobacco. We highlight results of the extant literature, hypothesize possible effects where research is lacking, and suggest where future studies might be warranted.
\end{abstract}

Keywords: Tobacco; Youth; Environmental Strategies; Local Policies

\section{INTRODUCTION}

\subsection{Tobacco and Youth}

Tobacco use continues to be the leading preventable cause of premature death in the United States, killing over 430,000 people yearly. Moreover, tobacco use costs from $\$ 50$ billion to $\$ 73$ billion in excess medical expenditures per year [1]. Most new smokers (59\%) were younger than age 18 when they first smoked cigarettes. Perhaps more importantly, $37 \%$ of smokers were under the age of 18 when they started smoking daily [2], highlighting the danger of youth initiation. Among new smokeless tobacco users, almost half (47.4\%) initiated use before age 18 .

Cigarette smoking during adolescence is associated with significant health problems, including increased number and severity of respiratory illnesses, decreased fitness, and potential retardation in the rate of lung growth [3]. Smokeless tobacco use among teenagers can lead to cardiovascular disease, oral cancer and gum disease [4]. Despite declines in youth tobacco use in recent years [5], state and national survey results are still cause for alarm. Data from the 2009 Monitoring the Future (MTF) survey show that $6.5 \%, 13.1 \%$ and $20.1 \%$ of $8^{\text {th }}, 10^{\text {th }}$, and $12^{\text {th }}$ graders, respectively, reported cigarette smoking in the past 30 days [6]. Everyday approximately 4000 young people between the ages of 12 and 17 years initiate cigarette smoking, and 1000 become daily cigarette smokers [2]. In addition, 2009 MTF results show that, while not at the peak levels seen in the mid-1990's, 30-day prevalence rates for smokeless tobacco use increased significantly in 2009, especially for boys, who represent the primary consumers. More specifically, male 30 -day prevalence rates were $6.5 \%$, $11.1 \%$, and $15.8 \%$ in Grades 8,10 , and 12 , respectively, compared to rates of $1.4 \%, 2.0 \%$, and $1.7 \%$ among girls [6].

\subsection{Environmental Strategies to Prevent and Reduce Youth Tobacco Use and Problems}

Although traditional school-based curricular programs 
are the most common strategy to prevent or reduce youth tobacco use, their effectiveness may be limited because young people are immersed in a broader social context in which tobacco is readily available $[7,8]$. Environmental approaches change this social context by focusing on policy, enforcement, and media campaigns [9-12]. Environmental strategies may impact tobacco use behaviors directly through decreased opportunities to obtain or use tobacco. They may also help foster social norms that discourage youth use and lessen the likelihood of adult provision. Strategies include those that target access via retail and social sources, clean air laws that restrict where individuals can smoke, school policies, and minor in possession laws. In addition, policies need to be accompanied by enforcement to ensure that policy violations carry penalties. Finally, mass media campaigns are necessary to educate the community regarding the problem and garner support for policy changes and enforcement resources [13]. Thus, the impact of environmental strategies may depend upon the implementation of a comprehensive approach whose effects are synergistic [14-16]. The Centers for Disease Control and Prevention recommend comprehensive programs as best practices [17].

Although some interventions to reduce youth tobacco use originate at the state or national level, others occur at the local level. For the purpose of this review, we focus on the latter. When we discuss "interventions", "strategies", and "approaches", we include the complement of environmental policies and enforcement that synergistically target youth tobacco use. Some strategies may target both cigarette smoking and smokeless tobacco use (e.g., retail access, taxation, outlet density), whereas others target cigarette smoking specifically (e.g., clean air laws). The two types have been shown to complement each other, since stricter cigarette policies may not only reduce cigarette use, but also the use of other tobacco products [18].

Implementation and evaluation of these strategies, however, has mainly focused on their impact on cigarette smoking and less attention has been given to their impact on smokeless tobacco use [19]. Where possible, we highlight the effects on both tobacco types. Most of our work is limited to research conducted in the United States, though we occasionally cite investigations from neighboring Canada.

\section{METHOD}

Studies for this review were identified using various Internet searches, including Pubmed and other computerized databases. We also reviewed references identified from bibliographies of pertinent articles and books and elicited suggestions from experts in the field of tobacco control. Independent extraction was conducted by multiple observers. For the sake of comparability, the analysis was limited to studies conducted in the United States and Canada. The final review includes investigations published in peer-reviewed journals that examined the associations of local US tobacco control policies with tobacco use, including smokeless tobacco, among youth.

To combine the results of the studies in a rigorous manner, we considered using quantitative statistical techniques. Sufficient quantitative data however, were often not available for key outcome variables. In addition, differences in local policy implementation made comparing results across studies of questionable validity. We opted instead to utilize a more qualitative approach.

\section{RESULTS}

\subsection{Policies Targeting Tobacco Prices}

Numerous studies at the national and state levels have shown that higher cigarette prices are related to decreased youth cigarette smoking [20-22]. Higher cigarette prices may affect youth smoking directly, by decreasing means to purchase, and indirectly, by changing smoking norms, both of which serve to reduce perceived availability [23]. While limited research has examined the relationship between smokeless tobacco prices and smokeless tobacco use at the state level, results are consistent with those found for cigarettes [24-26].

The extent to which differences in prices among local communities affects youth tobacco use merits further investigation. Differences in local prices, however, have been reported and suggest that local price influences use. Toomey et al. found that price of different brands of cigarettes varied by neighborhood characteristics and store type in one metropolitan area [27]. For the same brand of cigarettes, the maximum price was 1.7 to 1.8 times higher than the lowest price. Preliminary data from our ongoing NCI-funded study of local tobacco policies in California indicate that cigarette prices vary by $15 \%$ to $26 \%$ among 50 communities, from $\$ 5.36$ to $\$ 6.18$ per pack of Marlboro cigarettes, and \$ 5.48 to \$ 6.93 per pack of Newport cigarettes. Given that youth may be more responsive to cigarette and smokeless tobacco prices than adults [26,28-30], the examination of price variability of tobacco by community and its effect on youth smoking and smokeless tobacco use warrants attention.

\subsection{Policies Targeting Retail Access}

\subsubsection{Compliance Checks and Enforcement}

One of the more well-studied of the tobacco policies are those that seek to reduce youth access to tobacco 
through retail channels [17,31]. In July 1992, the federal government enacted the Synar Amendment (P.L. 103321, Section 1926), which required that states enact and enforce laws prohibiting the sale or distribution of cigarettes to individuals under the age of 18. By 2009, all states showed violation rates under the mandated $20 \%$ and 26 states had rates below 10\% [32].

Accompanying this federal action was the implementation of new laws and enforcement efforts implemented at the local level to help to reinforce federal efforts. Local youth access interventions generally involve a combination of compliance checks, penalties for violations, merchant education and training programs, and community education and mobilization. A compelling body of empirical evidence confirms that retailer compliance rates have increased, and cigarette sales to youth decreased, which may be largely attributable to the fact that even moderate increases in enforcement can substantially reduce tobacco sales to minors, especially when combined with media and other community and policy activities [33-41].

Results of investigations of the effects of reduced youth sales on youth use, however, remain inconclusive. Some studies have shown positive correlations between decreased youth sales and youth smoking [42-49]. In contrast, some studies found no significant relationship between reduced sales and use [50-52].

The relationship between retail access policies and smokeless tobacco use has been less well-studied. In the Biglan et al. investigation [42], results showed a reduction in smokeless tobacco use among $9^{\text {th }}$-grade boys. Soldz et al. reported community efforts to increase enforcement of youth-access provisions in Massachusetts were linked to a decline of lifetime smokeless tobacco use among middle school students from 1993 to 1996 [53]. It is possible that policies targeting youth cigarette purchases may generalize and discourage youth smokeless tobacco use. On the other hand, it is possible that smokeless tobacco may be substituted for cigarettes when policies focus largely on cigarette procurement (e.g., taxes on cigarettes, compliance with cigarette sales laws) and on smoking (clean air laws), rather than tobacco use more generally. Additional research is merited to investigate these plausible relationships.

There are at least four reasons why local youth access strategies may fall short of their desired goal. First, policies and enforcement may have to achieve some threshold of intensity in order to prevent youth from buying cigarettes [40, 51]. Second, even where sales rates are relatively low, the probability of purchase success can be very high with multiple attempts. Moreover, the density of outlets in a community may increase the likelihood of successful underage purchase simply by increasing op- portunity. Third, non-retail, or social, sources of tobacco may supplement or substitute for reduced retail availability [54-62]. These substitution effects can greatly limit the effectiveness retail access strategies. Finally, interventions targeting the entire population may have more potent effects than those focusing on youth only $[52,63]$.

\subsubsection{Tobacco Retailer Licensing}

One way for states and localities to maintain stricter control over retail compliance is to require that tobacco venders obtain licenses to sell tobacco products. Licensure policies both provide a readily accessible list of tobacco outlets, as well as generate funds that can be used towards enforcement efforts. As of 2004, 49 states and the District of Columbia required retail licensing of some kind to sell tobacco. Thirty-two states penalize businesses for violating tobacco licensing requirements. Licensure policies can complement other retail access policies and may help to reduce youth sales through several mechanisms. They can allow for more efficient enforcement because of the provision of a current list of tobacco vendors. In addition, license suspension or revocation can serve as a punishment for retailers violating youth access regulations. In turn, license fees can be earmarked to pay for enforcement and education. No published studies to date have examined the impact of licensure policies specifically on youth use or how local policies may complement those implemented at the state level.

\subsubsection{Outlet Density}

Regulating tobacco outlet density, commonly implemented at the local level represents another mechanism by which to decrease youth retail availability. Few studies, however, have examined tobacco outlet density and tobacco use. Schneider et al. assessed the geographic association between outlet density and income, race, and ethnicity at the tract level of analysis for one county in the Midwest. Census tracts with lower median household income, a higher percentage of African Americans, or a higher percentage of Latinos had a greater density of cigarette retail outlets [64]. Applying a spatial analytical approach, $\mathrm{Yu}$ et al. supported the association between high tobacco outlet density and socio-economically disadvantage areas in New Jersey [65]. Similarly, Hyland et al. and Laws et al. investigated the relationship between outlet density and neighborhood characteristics but did not examine associations between outlet density and actual smoking behavior $[66,67]$.

Results of the few investigations on the relationship between density and actual smoking behaviors have been mixed and inconclusive. Reid et al. found positive 
correlations between tobacco outlet density and smoking prevalence for counties with a higher percentage of African Americans [68]. Controlling for a range of confounders, Novak et al. reported that the youth living in the $75^{\text {th }}$ percentile in terms of outlet density were $13 \%$ more likely to have smoked in the past month than youth living in the bottom $25^{\text {th }}$ percentile [69]. In another study in Canada, a greater number of tobacco outlets near schools were found to be related to an increased likelihood that underage smokers would buy their own cigarettes [70]. Also, the prevalence of current smoking was found higher at schools in neighborhoods with the highest tobacco outlet density ( $>5$ outlets) compared to schools in neighborhoods without any tobacco outlets [71]. Looking at the adult population, Li et al. showed that high smoking prevalence in Massachusetts' communities was associated with higher density of tobacco outlets [72]. In contrast, Pokorny et al. found no association between density, defined as the number of outlets per youth ages 10 - 17 years, and smoking, alone or in interactions with gender, race, adult or peer users, perceived tobacco access, or ability to purchase [49]. In a study of Canadian high school neighborhoods, Lovato et al. reported that the number of tobacco outlets was unrelated to school smoking prevalence [73]. More recently, McCarthy et al. found that among high school and urban students, but not middle school or rural students, there was a small but significant relationship between tobacco outlet density near schools and students' reports of smoking initiation but not reports of established smoking [74]. No published studies have examined the impact of outlet density on smokeless tobacco use.

Associations between alcohol outlet density and drinking and alcohol-associated problems have been far more well-studied and may provide guidance concerning the relationship between local tobacco outlet density and tobacco use behaviors. Although some discrepancies have been reported [75,76], most studies have found significant associations between outlet density and adult alcohol consumption and problems, including violent crime, and motor vehicle accidents [77-83]. Alcohol outlet density has also been related to higher rates of underage drinking and driving and riding with drivers who are consuming alcohol [84]. This research also suggests that differences in alcohol outlet density on a small geographical scale (i.e., neighborhood) probably have little or no relation to drinking-related outcomes, whereas differences on a larger scale (e.g., zip codes) can significantly affect consumption and problems [76].

\subsection{Minor in Possession Policies}

Despite reduced access through policies targeting retail procurement, underage individuals are still able to obtain tobacco through non-retail, or social, sources. Croghan et al. found that $66 \%$ of occasional smokers and $25 \%$ of regular smokers acquired cigarettes through social channels [55]. Parents and friends are a particularly important source for new smokers [56]. Similarly, Huhtala et al. reported that $84 \%$ of daily/occasional snus (i.e., moist smokeless tobacco) users and $79 \%$ of experimental users acquired it from friends or acquaintances [85].

Implementation and enforcement of minor in possession (MIP) policies are aimed at reducing social access to tobacco products. Many states have adopted legislation that penalizes youth who purchase or possess tobacco. Penalties for violating these laws typically include fines, community service, tobacco awareness and education classes, as well as driving license suspension. Some have questioned the utility of such policies, however, because they are difficult to enforce and shift responsibility away from the suppliers of tobacco to minors [86,87]. Such approaches may also foster the perception of a forbidden fruit nature of tobacco and serve to heighten youth desire for tobacco products.

Few studies have examined the impact of local MIP laws and enforcement on youth tobacco use. Although results have varied, the general trend is promising regarding MIP policy effects on use. Livingood et al., reported that youth in two Florida counties with the highest level of MIP law enforcement had a significantly reduced likelihood of past 30-day smoking compared to youth in two Florida counties with the lowest level of enforcement [88]. In a twenty four-town randomized study, Jason et al. found that $15 \%$ - $24 \%$ of children fined for possession had quit smoking over a three-year follow-up period [89]. Using a multi-level analytical approach, data from this study also showed that student in towns with higher levels of MIP law enforcement had significantly smaller increase in rates of current smoking than students in towns with less enforcement [90]. Moreover, youth in towns with low level of MIP law enforcement had a significantly greater increase in the percentage of heavy smokers [91]. Lazovich et al. found that smoking prevalence was lower in Minnesota's counties that allowed MIP-cited youth to attend a tobacco diversion program than in counties without such programs [92], suggesting that MIP policies complemented with treatment programs might increase the effectiveness of the former. In contrast, Gottlieb et al. found that MIP citation was unrelated to future smoking intentions of youth in 14 east and central Texas communities, though study authors noted that differential policy enforcement by race and ethnicity might have influenced study results [93]. 


\subsection{Clean Air Laws}

Research on policies implemented at the state level provides strong evidence that laws restricting where individuals can smoke are associated with reduced smoking among youth [20,29,94-97]. Although these laws specifically target cigarette smoking, they may also reduce the use of other tobacco products, including smokeless tobacco [18]. In terms of their political and economic feasibility, several studies have shown that the implementation of local clean air laws in bars and restaurants do not have a negative impact on revenue and, in some cases, may even show financial benefits $[98,99]$. In terms of their impact on youth tobaccorelated attitudes and behaviors, there is some evidence that local policies are associated with stronger antismoking norms among youth [100]. Results regarding impact on youth use, however, have been inconclusive [23], with some research suggesting local policies may be associated with reduced youth use [101] and other research reporting no such association [102]. A complicating factor of this research, however, is that results of studies related to local interventions may be confounded by the effects of state laws, as well as other tobacco policies, such as tax hikes.

\subsection{Restrictions on Retail Marketing and Advertising Equations}

Since the 1998 Tobacco Master Settlement Agreement (MSA), the retail arena has become one of the few remaining channels that tobacco companies can use to target both minors and those legally permitted to purchase tobacco. A compelling body of evidence has consistently shown that tobacco marketing and promotion increases the likelihood that adolescents will initiate and use tobacco [103-107].

There is limited evidence regarding the local tobacco advertising and its effects on youth tobacco use. This lack is in part attributable to preemptive legislation at the state level that prohibits localities from enacting laws that vary or are stricter than state laws. As of Dec. 31, 2009, while fewer states still upheld such preemptions, 12 still enforced such restrictions [108]. Henriksen et al. found that stores where adolescents shopped most frequently contain more tobacco marketing than other stores in the same community [109]. A recent study by Seidenberg et al. found that storefront cigarette advertising differs by community demographic profile, such that advertisements in low-income/minority communities were more likely to be larger and promote menthol products [110]. Like several of the interventions cited above, methodological limitations of this body of research includes the difficulty of determining the differ- ential effects of state vs. local policies, and of marketing and advertising restrictions vs. other tobacco policies [107].

\section{CONCLUSIONS AND SUGGESTIONS FOR FUTURE RESEARCH}

State tobacco policies are widely advocated for reducing youth tobacco use. The purpose of these policies is to increase the effort and resources necessary for youth to obtain tobacco and the negative consequences for possession and use [12,111]. The effects of local policies are far less well-studied but appear to also reduce youth use and may complement state efforts. Local policies may also reinforce community norms against adults using tobacco and providing it to youth [41]. Local tobacco policies to prevent and reduce youth use often focus on increasing retailer compliance with underage tobacco sales laws but may also include implementation of outlet density restrictions, minor in possession laws, clean air laws, and restrictions on marketing.

Evidence regarding the effects of local policies on tobacco use by young people is mixed and has focused almost exclusively on smoking. Some studies have found no effects of local efforts on youth smoking [40,50]. More, however, have found reductions in smoking by youth following local policy implementation, suggesting this approach is a ripe area for advancing youth tobacco control [42,46,47,112-114].

A number of shortcomings can be noted in extant research on local tobacco policy and its impact on youth attitudes and behaviors. First, there is a paucity of studies examining associations between local tobacco policies and youth smokeless tobacco use. Second, while numerous investigations have examined the relationships of a specific local policy with youth tobacco availability and use, few have considered the effects of multiple policies and how their impact may unfold over time. Third, few, if any, studies have investigated the processes through which potential effects of local policies on youth tobacco use and trajectories may be mediated. As a result, little is known about how and why such policies may influence tobacco use behaviors. Fourth, although some studies have investigated how use of retail and social sources of tobacco are interrelated, additional research is necessary to establish how changes in retail availability influences the use of social and commercial sources of tobacco. Fifth, most studies of policies targeting underage tobacco users have rarely included other important factors known to influence use, such as community, social, psychological, and personal factors. Finally, most of the available research has been cross-sectional. Only a few studies have considered how differences in local environmental approaches to youth tobacco control may affect initiation to 
tobacco use and tobacco use trajectories over time.

To this end, we are currently conducting an NCIfunded study of the impact of local tobacco policies on youth tobacco attitudes and use in 50 cities in California. The study will proceed from a conceptual model that includes community-level variables (tobacco policies and availability, population density, SES, ethnic composition, community disorganization), as well as neighborhood and individual-level factors (smoking, smoking beliefs, perceived law enforcement, personal risk factors, background characteristics). The model specifies how the effects of community variables are mediated through and moderate the effects of individual-level variables. Multi-level regression and latent variable structural equations models will be used to investigate relations between local policies and smoking among youth in the communities and test hypotheses generated by the model. The long-term objective of the study is to provide a better understanding of how local tobacco policies and enforcement relate to adolescent smoking. This information in turn will provide a better basis for designing and implementing more effective community interventions to reduce and prevent adolescent smoking. Ultimately, the results from this study will help policymakers and community advocates make better decisions about prevention policies and the allocation of prevention resources.

\section{ACKNOWLEDGEMENTS}

This study was funded by the National Cancer Institute (NCI) Grant No. R01-CA138956 (Local Tobacco Policy and Youth Smoking) and the Tobacco-Related Disease Research Program (TRDRP; http://www. trdrp.org) Grant No. 19CA-016 (Retail Access to Tobacco and Youth Smoking Behavior).

\section{REFERENCES}

[1] US Department of Health and Human Services (2000) Youth tobacco surveillance-United States 1998-1999. MMWR CDC Surveillance Summary, 1-94.

[2] US Department of Health and Human Services (2009) Substance abuse and mental health services administration results from the 2008 national survey on drug use and health. National findings Substance Abuse and Mental Health Services Administration, Rockville.

[3] Arday, D.R., Giovino, G.A., Schulman, J., Nelson, D.E., Mowery, P. and Samet, J.M. (1995) Cigarette smoking and self-reported health problems among US high school seniors, 1982-1989. American Journal of Health Promotion, 10, 111-116.

[4] US Department of Health and Human Services (1986) The health consequences of using smokeless tobacco: Report of the advisory committee to the surgeon general. National Institutes of Health, Bethesda.

[5] Johnston, L.D., O’Malley, P.M., Bachman, J.G., Schulenberg, J.E. (2004) Cigarette smoking among American teens continues to decline, but more slowly than in the past. University of Michigan News and Information Services, Ann Arbor.

[6] Johnston, L.D., O’Malley, P.M., Bachman, J.G., Schulenberg, J.E. (2009) Smoking continues gradual decline among US teens, smokeless tobacco threatens a comeback. http://www.monitoringthefuture.org.

[7] Lantz, P.M., Jacobson, P.D., Warner, K.E., Wasserman, J., Pollack, H.A., Berson, J. and Ahlstrom, A. (2000) Investing in youth tobacco control: A review of smoking prevention and control strategies. Tobacco Control, 9, 47-63.

[8] US Department of Health and Human Services (1994) Preventing tobacco use among young people: A report of the Surgeon General. US Department of Health and Human Services, Public Health Service, Centers for Disease Control, Center for Chronic Disease and Health Promotion, Office on Smoking and Health, Rockville.

[9] Friend, K.B. and Ladd, G.T. (2009) Advertising and youth gambling: A review of the lessons learned from tobacco control. Drugs: Education, Prevention, and Policy, 16, 283-297. doi:10.1080/09687630701838026

[10] Friend, K. and Levy, D.T. (2002) Reductions in smoking prevalence and cigarette consumption associated with mass-media campaigns. Health Education Research, 17, 85-98. doi:10.1093/her/17.1.85

[11] Grube, J.W. and Nygaard, P. (2001) Adolescent drinking and alcohol policy. Contemporary Drug Problems, 28, 87-131.

[12] Ranson, M.K., Jha, P., Chaloupka, F.J. and Nguyen, S.N. (2002) Global and regional estimates of the effectiveness and cost-effectiveness of price increases and other tobacco control policies. Nicotine \& Tobacco Research, 4, 311-319.doi:10.1080/14622200210141000

[13] Levy, D.T. and Friend, K.B. (2000) A simulation model of tobacco youth access policies. Journal of Health Politics, Policy and Law, 25, 1023-1050. doi:10.1215/03616878-25-6-1023

[14] Bauer, U., Johnson, T., Hopkins, R. and Brooks, R. (2000) Changes in youth cigarette use and intentions following implementation of a tobacco control program: Findings from the Florida Youth Tobacco Survey, 1998-2000. The Journal of the American Medical Association, 284, 723-728. doi:10.1001/jama.284.6.723

[15] Burns, D.M. (2002) Reducing tobacco use: What works in the population? Journal of Dental Education, 66, 1051-1060.

[16] Levy, D.T. and Friend, K.B. (2003) The effects of clean indoor air laws: What do we know and what do we need to know? Health Education Research, 18, 592-609. doi:10.1093/her/cyf045

[17] Centers for Disease Control and Prevention (2007) Best practices for comprehensive tobacco control programs -October 2007. Department of Health and Human Services, Centers for Disease Control and Prevention, National Center for Chronic Disease Prevention and Health Promotion, Office on Smoking and Health, Atlanta.

[18] Mumford, E.A., Levy, D.T., Gitchell, J.G. and Blackman, K.O. (2006) Smokeless tobacco use 1992-2002: Trends and measurement in the Current Population Survey-Tobacco Use Supplements. Tobacco Control, 15, 166-171. doi:10.1136/tc.2005.012807

[19] Mumford, E.A., Levy, D.T., Gitchell, J.G. and Blackman, 
K.O. (2005) Tobacco control policies and the concurrent use of smokeless tobacco and cigarettes among men, 1992-2002. Nicotine \& Tobacco Research, 7, 891-900. doi:10.1080/14622200500266098

[20] Botello-Harbaum, M.T., Haynie, D.L., Iannotti, R.J., Wang, J., Gase, L. and Simons-Morton, B. (2009) Tobacco control policy and adolescent cigarette smoking status in the United States. Nicotine \& Tobacco Research, 11, 875-885. doi:10.1093/ntr/ntp081

[21] Carpenter, C. and Cook, P.J. (2007) Cigarette taxes and youth smoking: New evidence from national, state, and local Youth Risk Behavior Surveys. Journal of Health Economics, 27, 287-299.

doi:10.1016/j.jhealeco.2007.05.008

[22] Ross, H. and Chaloupka, F.J. (2003) The effect of cigarette prices on youth smoking. Journal of Health Economics, 12, 217-230. doi:10.1002/hec.709

[23] Liang, L., Chaloupka, F., Nichter, M. and Clayton, R. (2003) Prices, policies and youth smoking. Addiction, 98, 105-122. doi:10.1046/j.1360-0443.98.s1.7.x

[24] Chaloupka, F.J., Tauras, J.A. and Grossman, M. (1997) Public policy and youth smokeless tobacco use. Southern Economic Journal, 64, 503-516. doi:10.2307/1060863

[25] Goel, R.K. and Nelson, M.A. (2005) Tobacco policy and tobacco use: Differences across tobacco types, gender and age. Applied Economics, 37, 765-771. doi: 10.1080/0003684042000337415

[26] Ohsfeldt, R.L., Boyle, R.G. and Capilouto, E.L. (1998) Tobacco taxes, smoking restrictions, and tobacco use; 6486. National Bureau of Economic Research, Cambridge.

[27] Toomey, T.L., Chen, V., Forster, J.L., Van Coevering, P., and Lenk, K.M. (2009) Do cigarette prices vary by brand, neighborhood, and store characteristics? Public Health Reports, 124, 535-540.

[28] Ding, A. (2003) Youth are more sensitive to price changes in cigarettes than adults. The Yale Journal of Biology and Medicine, 76, 115-124.

[29] Tauras, J.A. and Chaloupka, F.J. (1999) Price, clean indoor air, and cigarette smoking: Evidence from longitudinal data for young adults. National Bureau of Economic Research Working Paper, No. W6937.

[30] Townsend, J., Roderick, P. and Cooper, J. (1994) Cigarette smoking by socioeconomic group, sex, and age: Affects of price, income, and health publicity. British Medical Journal, 309, 923-927.

[31] Wakefield, M. and Chaloupka, F. (2000) Effectiveness of comprehensive tobacco control programmes in reducing teenage smoking in the USA. Tobacco Control, 9, 177186. doi:10.1136/tc.9.2.177

[32] Center for Substance Abuse Prevention Number of States Achieving 20-Percent Non-compliance Target by Year; 2006 (2008).

http://www.samhsa.gov/samhsanewsletter/Volume_17_N umber_4/JulyAugust2009.pdf

[33] DiFranza, J.R. (1999) Are the federal and state governments complying with the Synar Amendment? Archives of Pediatrics and Adolescent Medicine, 153, 1089-1097.

[34] DiFranza, J.R. (2000) State and federal compliance with the Synar amendment: Federal fiscal year 1997. Archives of Pediatrics and Adolescent Medicine, 154, 936-942.

[35] DiFranza, J.R. (2001) State and federal compliance with the Synar Amendment: Federal fiscal year 1998. Archives of Pediatrics and Adolescent Medicine, 155, 572-578.

[36] Forster, J.L. and Wolfson, M. (1998) Youth access to tobacco: Policies and politics. Annual Review of Public Health, 19, 203-235. doi:10.1146/annurev.publhealth.19.1.203

[37] Levy, D.T. and Friend, K. (2000) Gauging the effects of mass media policies: what do we need to know? Journal of Public Health Management and Practice, 6, 95-106.

[38] Levy, D.T. and Friend, K.B. (2002) Strategies for reducing youth access to tobacco: A framework for understanding empirical findings on youth access policies. Drugs: Education, Prevention, and Policy, 9, 285-303. doi:10.1080/09687630210129538

[39] Levy, D.T., Friend, K., Holder, H. and Carmona, M. (2001) Effect of policies directed at youth access to smoking: Results from the SimSmoke computer simulation model. Tobacco Control, 10, 108-116. doi:10.1136/tc.10.2.108

[40] Rigotti, N.A., DiFranza, J.R., Chang, Y.C., Tisdale, T., Kemp, B. and Singer, D.E. (1997) The effect of enforcing tobacco-sales laws on adolescents' access to tobacco and smoking behavior. New England Journal of Medicine, 337, 1044-1051. doi:10.1056/NEJM199710093371505

[41] Rohrbach, L.A., Howard-Pitney, B., Unger, J.B., Dent, C. W., Howard, K.A., Cruz, T.B., Ribis, K.M., Norman, G.J. Fishbein and H., Johnson, C.A. (2002) Independent evaluation of the California tobacco control program: Relationships between program exposure and outcomes, 1996-1998. American Journal of Public Health, 92, 975-983. doi:10.2105/AJPH.92.6.975

[42] Biglan, A., Ary, D., Smolkowski, K., Duncan, T. and Black, C. (2000) A randomised controlled trial of a community intervention to prevent adolescent tobacco use. Tobacco Control, 9, 24-32. doi:10.1136/tc.9.1.24

[43] Dent, C. and Biglan, A. (2005) Relation between access to tobacco and adolescent smoking. Tobacco Control, 13, 334-338. doi:10.1136/tc.2003.004861

[44] DiFranza, J.R. and Brown, L.J. (1992) The Tobacco Institute's "It's the Law" campaign: Has it halted illegal sales of tobacco to children? American Journal of Public Health, 82, 1271-1273. doi:10.2105/AJPH.82.9.1271

[45] DiFranza, J.R., Savageau, J.A. and Fletcher, K.E. (2009) Enforcement of underage sales $\mathrm{l}$ aws as a predictor of daily smoking among adolescents: A national study. BMC Public Health, 9, 107. doi: 10.1186/1471-2458-9-107.

[46] Forster, J.L., Murray, D.M., Wolfson, M., Blaine, T.M. Wagenaar, A.C. and Hennrikus, D.J. (1998) The effects of community policies to reduce youth access to tobacco. American Journal of Public Health, 88, 1193-1198. doi:10.2105/AJPH.88.8.1193

[47] Jason, L.A., Ji, P.Y., Anes, M.D. and Birkhead, S.H. (1991) Active enforcement of cigarette control laws in the prevention of cigarette sales to minors. The Journal of the American Medical Association, 266, 3159-3161. doi:10.1001/jama.266.22.3159

[48] Jason, L.A., Pokorny, S.B. and Schoeny, M.E. (2003) Evaluating the effects of enforcements and fines on youth smoking. Critical Public Health, 13, 33-45. doi:10.1080/0958159031000100189

[49] Pokorny, S.B., Jason, L.A. and Schoeny, M.E. (2003) The relation of retail tobacco availability on initiation 
and continued cigarette smoking. Journal of Clinical Child and Adolescent Psychology, 32, 193-204.

doi:10.1207/S15374424JCCP3202 4

[50] Fichtenberg, C. and Glantz, S. (2002) Youth access interventions do not affect youth smoking. Pediatrics, 109, 1088-1092. doi:10.1542/peds.109.6.1088

[51] Stead, L.F. and Lancaster, T. (2000) A systematic review of interventions for preventing tobacco sales to minors. Tobacco Control, 9, 169-176. doi:10.1136/tc.9.2.169

[52] Thomson, C.C., Hamilton, W.L., Siegel, M.B., Biener, L. and Rigotti, N.A. (2007) Effects of local youth-access regulations on progression to established smoking among youths in Massachusetts. Tobacco Control, 16, 119-126. doi:10.1136/tc.2006.018002

[53] Soldz, S., Kreiner, P., Clark, T.W. and Krakow, M. (2000) Tobacco use among Massachusetts youth: Is tobacco control working? Preventive Medicine, 31, 287-296. doi:10.1006/pmed.2000.0727

[54] Centers for Disease Control and Prevention (2002) Usual sources of cigarettes for middle and high school students -Texas, 1998-1999. Centers for Disease Control and Prevention (CDC), 900.

[55] Croghan, E., Aveyard, P., Griffin, C. and Cheng, K.K. (2003) The importance of social sources of cigarettes to school students. Tobacco Control, 12, 67-73. doi:10.1136/tc.12.1.67

[56] DiFranza, J.R. and Coleman, M. (2001) Sources of tobacco for youths in communities with strong enforcement of youth access laws. Tobacco Control, 10, 323-328. doi:10.1136/tc.10.4.323

[57] Friend, K., Carmona, C., Wilbur, P. and Levy, D. (2001) Youths' social sources of tobacco. Contemporary Drug Problems, 28, 507-26.

[58] Klonoff, E.A., Landrine, H., Lang, D., Alcaraz, R. and Figueroa-Moseley, C. (2001) Adults buy cigarettes for underaged youths. American Journal of Public Health, 91, 1138-1139. doi:10.2105/AJPH.91.7.1138

[59] Ma, G.X., Shive, S., Legos, P. and Tan, Y. (2003) Ethnic differences in adolescent smoking behaviors, sources of tobacco, knowledge and attitudes toward restriction policies. Addictive Behaviors, 28, 249-268. doi:10.1016/S0306-4603(01)00225-8

[60] Shive, S., Ma, G.X. and Shive, E. (2001) A study of young adults who provide tobacco products to minors. Journal of School Health, 71, 218-222. doi:10.1111/j.1746-1561.2001.tb01320.x

[61] Von Bothmer, M.I.K., Mattsson, B. and Fridlund, B. (2002) Influences on adolescent smoking behaviour: Siblings' smoking and norms in the social environment do matter. Health \& Social Care in the Community, 10, 213-220. doi:10.1046/j.1365-2524.2002.00363.x

[62] Wolfson, M., Forster, J.L., Claxton, A.J. and Murray, D.M. (1997) Adolescent smokers' provision of tobacco to other adolescents. American Journal Public Health, 87, 649-651. doi:10.2105/AJPH.87.4.649

[63] Siegel, M., Albers, A.B., Cheng, D.M., Hamilton, W.L. and Biener, L. (2008) Local restaurant smoking regulations and the adolescent smoking initiation process: results of a multilevel contextual analysis among Massa- chusetts youth. Archives of Pediatrics and Adolescent Medicine, 162, 477-483.

doi:10.1001/archpedi.162.5.477

[64] Schneider, J.E., Reid, R.J., Peterson, N.A., Lowe, J.B. and Hughey, J. (2005) Tobacco outlet density and demographics at the tract level of analysis in Iowa: Implications for environmentally based prevention initiatives. Prevention Science, 6, 319-325. doi:10.1007/s11121-005-0016-z

[65] Yu, D., Peterson, N.A., Sheffer, M.A., Reid, R.J. and Schnieder, J.E. (2010) Tobacco outlet density and demographics: Analysing the relationships with a spatial regression approach. Public Health, 124, 412-416. doi:10.1016/j.puhe.2010.03.024

[66] Hyland, A., Travers, M.J., Cummings, K.M., Bauer, J. Alford, T., Wieczorek, W.F. (2003) Tobacco outlet density and demographics in Erie County, New York. American Journal of Public Health, 93, 1075-1076. doi:10.2105/AJPH.93.7.1075

[67] Laws, M.B., Whitman, J., Bowser, D.M. and Krech, L. (2002) Tobacco availability and point of sale marketing in demographically contrasting districts of Massachusetts. Tobacco Control, 11, 71-73.

[68] Reid, R.J., Peterson, N.A., Lowe, J.B. and Hughey, J. (2005) Tobacco outlet density and smoking prevalence: Does racial concentration matter? Drugs: Education Prevention and Policy, 12, 233-238. doi: 10.1080/09687630500035485

[69] Novak, S.P., Reardon, S.F., Raudenbush, S.W. and Buka, S.L. (2006) Retail tobacco outlet density and youth cigarette smoking: A propensity-modeling approach. American Journal of Public Health, 96, 670-676. doi:10.2105/AJPH.2004.061622

[70] Leatherdale, S.T. and Strath, J.M. (2007) Tobacco retailer density surrounding schools and cigarette access behaviors among underage smoking students. Annals of Behavioral Medicine, 33, 105-111. doi:10.1207/s15324796abm3301_12

[71] Henriksen, L., Feighery, E., Schleicher, N., Cowling, D., Kline, R. and Fortmann, S. (2008) Is adolescent smoking related to the density and proximity of tobacco outlets and retail cigarette advertising near schools? Preventive Medicine, 47, 210-214. doi: 10.1016/j.ypmed.2008.04.008

[72] Li, W., Land, T., Zhang, Z., Keithly, L. and Kelsey, J.L. Small-area estimation and prioritizing communities for tobacco control efforts in Massachusetts. American Journal of Public Health, 99, 470-479. doi:10.2105/AJPH.2007.130112

[73] Lovato, C.Y., Hsu, H.C., Sabiston, C.M., Hadd, V. and Nykiforuk, C.I. (2007) Tobacco point-of-purchase marketing in school neighbourhoods and school smoking prevalence: A descriptive study. Canadian Journal of Public Health, 98, 265-270.

[74] McCarthy, W.J., Mistry, R., Lu, Y., Patel, M., Zheng, H. and Dietsch, B. (2009) Density of tobacco retailers near schools: Effects on tobacco use among students. American Journal of Public Health, 99, 2006-2013. doi:10.2105/AJPH.2008.145128

[75] Gorman, D.M., Speer, P.W., Labouvie, E.W. and Subaiya, A.P. (1998) Risk of assaultive violence and alcohol availability in New Jersey. American Journal of Public 
Health, 88, 97-100. doi:10.2105/AJPH.88.1.97.

[76] Gruenewald, P.J., Millar, A., Ponicki, W.R. and Brinkley, G. (2000) Physical and economic access to alcohol: The application of geostatistical methods to small area analysis in community settings. In: Wilson, R.A. and Dufour, M.C., Eds., The epidemiology of alcohol problems in small geographic areas, National Institute on Alcohol Abuse and Alcoholism, Bethesda, 163-212.

[77] Livingston, M. (2008) Alcohol outlet density and assault: A spatial analysis. Addiction, 103, 619-628. doi:10.1111/j.1360-0443.2008.02136.x

[78] Scribner, R., Mason, K., Theall, K., Simonsen, N., Schneider, S.K., Towvim, L.G. and Dejong, W. (2008) The contextual role of alcohol outlet density in college drinking. Journal of Studies on Alcohol and Drugs, 69, 112-120.

[79] Scribner, R.A., Cohen, D.A. and Fisher, W. (2000) Evidence of a structural effect for alcohol outlet density: A multilevel analysis. Alcoholism: Clinical and Experimental Research, 24, 188-195. doi: 10.1111/j.1530-0277.2000.tb04590.x

[80] Scribner, R., Cohen, D., Kaplan, S. and Allen, S.H. (1999) Alcohol availability and homicide in New Orleans: Conceptual considerations for small area Analysis of the effect of alcohol outlet density. Journal of Studies on Alcohol, 60, 310-316.

[81] Scribner, R.A., MacKinnon, D.P. and Dwyer, J.H. (1994) Alcohol outlet density and motor vehicle crashes in Los Angeles County cities. Journal of Studies on Alcohol, 55, 447-453.

[82] Speer, P.W., Gorman, D.M., Labouvie, E.W. and Ontkush, M.J. (1998) Violent crime and alcohol availability: Relationships in an urban community. Journal of Public Health Policy, 19, 303-318. doi:10.2307/3343538

[83] Treno, A.J., Johnson, F.W., Remer, L.G. and Gruenewald, P.J. (2007) The impact of outlet densities on alcohol related crashes: A spatial panel approach. Accident Analysis \& Prevention, 39, 894-901. doi:10.1016/j.aap.2006.12.011

[84] Treno, A.J., Grube, J.W. and Martin, S. (2003) Alcohol outlet density as a predictor of youth drinking and driving: a hierarchical analysis. Alcoholism: Clinical \& Experimental Research, 27, 835-840. doi:10.1097/01.ALC.0000067979.85714.22

[85] Huhtala, H.S.A., Rainio, S.U. and Rimpela, A.H. (2006) Adolescent snus use in Finland in 1981-2003: Trend, total sales ban and acquisition. Tobacco Control, 15, 392397. doi:10.1136/tc.2005.015313

[86] Cismoski, J. (1994) Blinded by the light: The folly of tobacco possession laws against minors. Wisconsin Medical Journal, 93, 591-598.

[87] Wolfson, M. and Hourigan, M. (1997) Unintended consequences and professional ethics: Criminalization of alcohol and tobacco use by youth and young adults. Addiction, 92, 1159-1164. doi:10.1111/j.1360-0443.1997.tb03675.x

[88] Livingood, W.W., Woodhouse, C.D., Sayre, J.J. and Wludka, P. (2001) Impact study of tobacco possession law enforcement in Florida. Health Education \& Behavior, 28, 733-748. doi:10.1177/109019810102800606

[89] Jason, L.A., Pokorny, S.B., Adams, M., Hunt, Y.,
Gadiraju, P. and Schoeny, M. (2007) Do fines for violating possession-use-purchase laws reduce youth tobacco use?. Journal of Drug Education, 37, 393-400. doi:10.2190/DE.37.4.C

[90] Jason, L.A., Pokorny, S.B. and Adams, M. (2008) A randomized trail evaluating tobacco possession-use-purchase laws in the USA. Social Science \& Medicine, 67, 1700-1707. doi:10.1016/j.socscimed.2008.09.028

[91] Jason, L.A., Pokorny, S.B., Adams, M., Topliff, A., Harris, C.H. and Hunt, Y. (2009) Effects of youth tobacco access and possession policy interventions on heavy adolescent smokers. International Journal of Environmental Research and Public Health, 6, 1-9. doi:10.3390/ijerph6010001

[92] Lazovich, D., Forster, J., Widome, R. and Van Coevering, P. (2006) Tobacco possession, use, and purchase laws and penalties in Minnesota: Enforcement, tobacco diversion programs, and youth awareness. Nicotine \& Tobacco Research, 9, S57-S65. doi:10.1080/14622200601083475

[93] Gottlieb, N.H., Loukas, A., Corrao, M., McAlister, A., Snell, C. and Huang, P.P. (2004) Minors' tobacco possession law violation and intentions to smoke: Implications for tobacco control. Tobacco Control, 13, 237-243. doi:10.1136/tc. 2003.003988

[94] Levy, D.T. and Friend, K. (2001) A framework for evaluating and improving clean indoor air laws. Journal of Public Health Management and Practice, 7, 87-96.

[95] Levy, D.T. and Friend, K. (2001) A computer simulation model of mass media interventions directed at tobacco use. Preventive Medicine, 32, 284-294. doi:10.1006/pmed.2000.0808

[96] Wakefield, M.A., Chaloupka, F.J., Kaufman, N.J., Orleans, C.T., Barker, D.C. and Ruel, E.E. (2000) Effect of restrictions on smoking at home, at school, and in public places on teenage smoking: Cross sectional study. British Medical Journal, 321, 333-337. doi:10.1136/bmj.321.7257.333

[97] Wasserman, W.G., Manning, W.G., Newhouse, J.P. and Winkler, J.D. (1991) The effects of excise taxes and regulations on cigarette smoking. Journal of Health Economics, 10, 43-64. doi:10.1016/0167-6296(91)90016-G

[98] Collins, N.M., Shi, Q., Forster, J.L., Erickson, D.J. and Toomey, T.L. (2010) Effects of clean indoor air laws on bar and restaurant revenue in Minnesota cities. American Journal of Preventive Medicine, 39, S10-S15. doi:10.1016/j.amepre.2010.09.011

[99] Erickson, M. and Chaloupka, F. (2007) The economic impact of clean indoor air laws. CA: A Cancer Journal for Clinicians, 57, 367-78. doi:10.3322/CA.57.6.367

[100] Hamilton, W.L., Biener, L. and Brennan, R.T. (2008) Do local tobacco regulations influence perceived smoking norms? Evidence from adult and youth surveys in Massachusetts. Health Education Research, 23, 709-722. doi:10.1093/her/cym054

[101] McMullen, K.M., Brownson, R.C., Luke, D. and Chriqui, J. (2005) Strength of clean indoor air laws and smoking related outcomes in the USA. Tobacco Control, 14, 43-48. doi:10.1136/tc.2004.007880

[102] Klein, E.G., Forster, J.L., Erickson, D.J., Lytle, L.A. and 
Schillo, B. (2009) The relationship between local clean indoor air policies and smoking behaviors in Minnesota youth. Tobacco Control, 18, 132-137. doi:10.1136/tc.2007.024307

[103] Choi, W.S., Ahluwalia, J.S., Harris, K.J. and Okuyemi, K. (2002) Progression to established smoking: The influence of tobacco marketing. American Journal of Preventive Medicine, 22, 228-233. doi:10.1016/S0749-3797(02)00420-8

[104] DiFranza, J.R., Wellman, R.J., Sargent, J.D., Weitzman, M., Hipple, B.J. and Winickoff, J.P. (2006) Tobacco promotion and the initiation of tobacco use: Assessing the evidence for causality. Pediatrics, 117, 1237-1248. doi:10.1542/peds.2005-1817

[105] Henriksen, L., Schleicher, N.C., Feighery, E.C. and Fortmann, S.P. (2010) A longitudinal study of exposure to retail cigarette advertising and smoking initiation. Pediatrics, 126, 232-238. doi:10.1542/peds.2009-3021

[106] Paynter, J. and Edwards, R. (2009) The impact of tobacco promotion at the point of sale: A systematic review. Nicotine \& Tobacco Research, 11, 25-35. doi:10.1093/ntr/ntn002

[107] Slater, S.J., Chaloupka, F.J., Wakefield, M., Johnston, L. D. and O’Malley, P.M. (2007) The impact of retail cigarette marketing practices on youth smoking uptake. Archives of Pediatrics and Adolescent Medicine, 161, 440445. doi:10.1001/archpedi.161.5.440

[108] Centers for Disease Control and Prevention (2010) State Preemption of Local Smoke-Free Laws in Government Work Sites, Private Work Sites, and Restaurants-United
States, 2005-2009. Morbidity and Mortality Weekly Report, 59, 105-108.

[109] Henriksen, L., Feighery, E.C., Schleicher, N.C., Haladjian, H.H. and Fortmann, S.P. (2004) Reaching youth at the point of sale: Cigarette marketing is more prevalent in stores where adolescents shop frequently. Tobacco Control, 13, 315-318. doi:10.1136/tc.2003.006577

[110] Seidenberg, A.B., Caughey, R.W., Rees, V.W. and Connolly, G.N. (2010) Storefront cigarette advertising differs by community demographic profile. American Journal Health Promotion, 24, 26-31. doi:10.4278/ajhp.090618-QUAN-196

[111] Chaloupka, F. and Wechsler, H. (1997) Price, tobacco control policies and smoking among young adults. Journal of Health Economics, 16, 359-373. doi:10.1016/S0167-6296(96)00530-9

[112] Altman, D.G. and Wheelis, A.Y. (1999) The relationship between tobacco access and use among adolescents: A four community study. Social Science \& Medicine, 48, 759-775. doi:10.1016/S0277-9536(98)00332-3

[113] Jason, L., Billows, W., Schnopp-Wyatt, D. and King, C. (1996) Reducing the illegal sales of cigarettes to minors: Analysis of alternative enforcement schedules. Journal of Applied Behavior Analysis, 29, 333-344. doi:10.1901/jaba.1996.29-333

[114] Siegel, M., Biener, L. and Rigotti, N.A. (1999) The Effect of Local Tobacco Sales Laws on Adolescent Smoking Initiation. Preventive Medicine, 29, 334-342. doi:10.1006/pmed.1999.0551 